\title{
A Conceptual User Experience Evaluation Model on Online Systems
}

\author{
Norhanisha Yusof ${ }^{1}$, Nor Laily Hashim ${ }^{2}$, Azham Hussain ${ }^{3}$ \\ Department of Information Technology and Communication, Politeknik Balik Pulau, Penang, Malaysia ${ }^{1}$ \\ School of Computing, Universiti Utara Malaysia, Kedah, Malaysia ${ }^{2,3}$
}

\begin{abstract}
An online system has become a priority for organisations or companies in many countries, as it allows many processes to be conducted via online platforms, which contributes to profit gain. There are different types of user experience (UX) evaluation models that have been proposed to guide the measurement and development process. However, most of these models only have dimensions, and there is no guidance for UX measurement on online systems. The lack of evaluation models for online system measurement requires further investigation. This paper aims to identify the gaps in UX evaluation models, and develop a conceptual UX evaluation model for online systems. The method used in this study includes reviewing several literatures and shortlisting the relevant publications on UX and online systems. After that, the gaps were identified from the existing UX evaluation model in the relevant publications based on the ISO standard. Then, the study identified the important components of UX, and proposed a new conceptual UX evaluation model for online systems. The results of the study are the identification of the gaps in existing $U X$ evaluation models, and the development of a new conceptual UX evaluation model that is specifically for online systems. Therefore, the results help in considering UX dimensions, criteria, and metrics and potential UX components for evaluation and measurement. The paper contributes to system developers, designers, and also researchers for future UX evaluation model development for online systems. Future studies could use the reviewed UX evaluation models to identify relevant dimensions of online systems, and hence improve the model that they will develop. The findings may also be beneficial to organisations that own online systems by providing guidelines on important dimensions involved in their UX-based evaluations.
\end{abstract}

Keywords-User experience; UX evaluation; UX model; online system; conceptual model

\section{INTRODUCTION}

Since the beginning of the millennium, computers have been widely utilised in various countries, resulting in a revolution in information and communication technology (ICT), known as the digital revolution. The digital revolution has rapidly grown in developed countries, where there are various applications or electronic systems in use. Nowadays, an online system is one of the most important applications of ICT that has become a priority in all systems around the world. An online system is a platform used by any individual or organisation to perform their work through the Internet, whereby it is flexible and accessible to users [1]. Online systems might be totally secure, or could allow third-party programmes to join via programming platforms. Online systems are useful tools for storing, organising, utilising, and gathering data. Nowadays, online platforms have been modernised, whereby the users can have access to all information at their fingertips. The users use the Internet in their daily lives to get information, shop, and communicate with chosen online systems. This priority is quickly expanding in emerging countries because it can help manage any transaction easily. Many governments and businesses support the delivery of online systems, which allows them to leverage existing technology transactions and interactions with higher efficiency and easy access [2]. There are many online systems; for example, eBay, Craigslist, Amazon Marketplace, Airbnb, and Uber [3], [4]. An online system is not only for business purposes, but it is also for government systems, such as egovernment [5] and e-procurement system, because it can integrate the use of ICT to improve customer, supplier, and other relationships [6].

The study of online systems is a significant part of today's economy. For example, the potential of an online system to contribute total profitability to governments and companies is enormous. It is important to remember that every dollar saved in terms of cost because of using an online system can directly contribute to the productivity of the country. The study of online systems is significant for a variety of reasons, including the fact that many industrialised countries and business companies use them to manage relationships with their users [4]. The benefits of online systems are as follows: easy to use, quick response time, automatically processed via technology, and faster in terms of accessing information because it is online worldwide.

User experience (UX) is the perception and reaction of realworld users towards real products and services. UX, as defined by ISO 9241-11 (2018), which is the perceptions and responses of a person as a result of the use or anticipated use of a product, system, or service [7]. Besides that, UX is also related to users' emotions, beliefs, and physical and psychological responses. It also incorporates brand image, presentation, system performance, and physical state as a result of earlier experiences, attitudes, skills, and personality, among other things [8]. The term UX is most commonly associated with the design and presentation of online software solutions such as websites and applications [9]. Thus, UX is an important factor in creating quality products, systems, and services, especially for online systems because many users use online platforms in their daily lives and the impact needs to be known through an evaluation. UX evaluation is one way of analysing individuals' experiences [10]. UX evaluation is a burgeoning field with a wide range of approaches [11]. One of the most important 
aspects of studying UX is evaluation, which refers to the use of a set of procedures and tools with the goal of determining how people feel about using a system or product [8].

However, there is a lack of investigation of the user experience related to an online system in literature as explored by the authors. For example, the study by [12] explored the emotions of online learning systems among college teachers, and proposed an integrated model of Technology Acceptance Model (TAM); however, they emphasised on identification of technology usage intentions among the teachers, and the study did not involve UX dimensions except emotion only. There are also some researchers who focus more on factors influencing UX [13] but overlooked UX evaluation, including coming up with a conceptual UX evaluation model for an online system with important measurements. Besides that, the study by [14] proposed a conceptual model for UX whereby it is related to the process of UX practices in organisations. The model does not focus on evaluating UX of online systems and does not discuss the model in terms of UX components from instrumental and non-instrumental qualities perspectives. UX components can be defined as important aspects of humantechnology interaction [15]. For example, instrumental and non-instrumental qualities are important in a UX model measurement because they are core components of experiences related to the user perception including emotion while users are using the system [16]. On the other hand, [17] have developed a new conceptual UX model for evaluation that focuses on workers' performance evaluation, and not on the online system. Furthermore, the need to conduct this study is motivated by the lack of existing models that were more focused on specific systems such as e-commerce [18], ebanking [19], and mobile [20]. Furthermore, these studies do not provide clear and comprehensive measurement for general online systems.

The gaps discussed above have motivated the authors to study UX that is related to online systems by identifying the required dimensions and main components of the conceptual model that can be referenced for UX measurement on online systems. Therefore, the gaps in existing UX evaluation models need to be identified with a conceptual UX evaluation model development for a better measurement.

The objective of this current research is to identify the gaps in the existing UX evaluation models and develop a conceptual UX evaluation model for online systems. The research questions (RQ) addressed in this paper is as follows:

RQ 1: What are the gaps in UX evaluation model for online systems?

RQ 2: What are dimensions of a conceptual UX evaluation model for online systems?

This paper is organised as follows: Section 2 presents the background of online systems and relates to a user UX; Section 3 discusses the methodology of the study; Section 4 discusses the results and discussion regarding existing UX evaluation model including conceptual model development; and Section 5 provides the concluding remarks and future work for this paper.

\section{BACKGROUND}

This section presents the research studies in the literature related to UX evaluation, which covers the content. The gaps in the existing UX evaluation models discovered in the literature review are considered in the newly developed conceptual UX evaluation model for online systems.

\section{A. Evaluation}

UX has become a more prominent part of system development, following the growth of business and process models. UX is influenced by the user's internal state, for example, individual motivations, expectations, needs, and mood; the characteristics of the system being used, such as complexity, usability, and functionality; and it is also associated with interactions of the context or environment with the system [21]. The analysis of user interaction related to web systems is crucial for satisfaction, and it may even encourage changes to improve UX level [22]. There are five points in UX concepts, which are understanding of research, sketch, design, implement, and evaluation [1]. One of the pillars of academic UX research has been identified as evaluation [11]. The experience evaluation is crucial for UX practitioners in the workplace [11]. UX evaluation depends on the components or factors that exist in the models [23]. Thus, UX encompasses product aspects and individual aspects, whereby these consist of users' perception such as pragmatic and hedonic quality, aesthetics, user's emotional experiences, expectations, and needs [21].

In the literature review, many UX evaluation studies of online systems only have dimensions and criteria [15], [18][20], [24]. However, they are lacking the UX dimensions, criteria, and metrics in the UX evaluation models. Having the dimension, criteria, and metric of the model for measurement is important because the organisation or stakeholder can have a clear understanding of how to conduct an evaluation of the product or system usage more specifically. Furthermore, there is a need for conceptual UX evaluation models for online systems because this model fills the gap in the literature of UX and online systems, including providing important dimensions; and it is also due to the studies on UX evaluation that did not define additional concrete UX dimensions [11]. Moreover, the conceptual UX evaluation model was developed since there was a lack of user experience studies on online systems after the publication review was conducted by the researcher. From the reviews conducted on this domain and to the best of the authors' knowledge, there is no work focused on the UX evaluation model for online systems yet. Furthermore, UX is still a blurred conceptualisation, causing the need for this study to be conducted [9]. Therefore, this study has developed a conceptual UX evaluation model for online systems.

\section{B. UX of Online Systems}

With the growth of Information and Communication Technology (ICT) nowadays, information can be obtained through an online system, social media, chat, and others [25]. Through the circulation of technology nowadays, many organisations or companies use online system platforms for various processes and transactions. It is publicly accessible, open, and more convenient. Thus, the user experience should be designed for human use as well, with easy access and 
assistance for user limitations such as reading small texts [1]. However, there is still a lack of research conducted related to UX and evaluation for online systems. From a conceptual standpoint, different researchers have varying interpretations of what UX is to suit their studies and application needs. Some studies argue that UX is holistic; others suggest that the complexity of experience should be broken down into evaluative components.

Based on the analysis of the existing models, it has been noted that the field of UX research should also be given attention in terms of measurement models [13]. UX can be associated with users' affective, cognitive views such as hedonic quality, attractiveness, and the subjective perception made by the users of a product, system, or services [9]. However, additional research is needed into how these qualities with UX dimensions can be represented in a more precise manner. Moreover, certain important dimensions that have a significant impact on user experience remain implicit in certain models [13]. Thus, a conceptual model for UX modelling should be established to comprehend, explore, and analyse interactions between users and products [13]. Defining a conceptual UX evaluation model can be considered by incorporating UX dimensions, criteria, and metrics in modelling and reflecting elements that have a direct impact on the user experience and online systems. The author in [17] developed a new conceptual UX model for evaluation called the TAMUX model, but it is for workers' performance evaluation and not for online systems. TAMUX is the combination of the Technology Acceptance Model (TAM) and the Components of user experience (CUE) model. The weaknesses of the conceptual model by [17] is it is lacking in terms of dimensions with criteria because it only has components such as task characteristic, individual characteristic, system characteristic, and performance effect.

Meanwhile, the current study by [25] conducted an evaluation of an online learning programme to investigate user experience improvement. However, the evaluation in Chow's research is more concerned about usability with the five dimensions of learnability, efficiency, memorability, errors, and satisfaction. There is no conceptual UX model that can be used or referred to for online system measurement. Therefore, these studies show the need for a conceptual model that consists of UX dimensions, criteria, and metrics because the measurement can be conducted in a more clearly and directed manner. Moreover, the development of conceptual the UX evaluation model also helps or enables organisation or business stakeholders to define and redefine the metrics in order to improve their user interface and users' experience [26]. The next section will discuss further on methodology and analysis of findings to answer the RQ as stated in the earlier section.

\section{METHODOLOGY}

This study used online databases such as 'Scopus' and 'Elsevier Science Direct' to search for previous literature. The searching technique in this study is referring to [27] study as a guidance. The review considers publications on user experience, UX, models, and systems for nine years from January 2013 to 15 October 2021. Only articles written in English and final published journals were considered for this study. Keywords such as 'user experience', 'UX', 'model', and 'online system' were used to search for articles in databases. 'Paper title' or 'abstract' or 'paper keywords' were the search criteria. The researcher found an entire list of all relevant publications by using multiple keyword combinations. From all these databases, the initial search yielded roughly 503 research publications.

Then, 503 of these papers were screened based on title and abstract. The screening method eliminated articles such as reports, book reviews, and review papers. The papers that passed the screening were subsequently scrutinised for appropriateness for online systems by evaluating a manuscript. Approximately 227 papers were screened through manuscript review and selection criteria. Then, only six papers were shortlisted and further investigated after reading the entire text. After completing the reading, irrelevant publications were filtered out based on the scholarly judgement. The result of final papers shows that there is a lack of UX model evaluation for online systems. Table I shows the results of the final review from databases, which resulted in a final shortlist of six relevant publications by the authors. While Fig. 1 shows the flow of literature review method.

TABLE I. REVIEW PAPERS FROM DATABASES

\begin{tabular}{|c|c|c|c|c|}
\hline Databases & Keyword used & $\begin{array}{l}\text { Result } \\
\text { based on } \\
\text { keyword }\end{array}$ & $\begin{array}{l}\text { Result } \\
\text { based on } \\
\text { title and } \\
\text { abstract }\end{array}$ & $\begin{array}{l}\text { Final } \\
\text { shortlist }\end{array}$ \\
\hline \multirow[t]{2}{*}{ Scopus } & $\begin{array}{l}\text { 'user experience' } \\
\text { AND 'model' } \\
\text { AND ‘online } \\
\text { system’ }\end{array}$ & 105 & 24 & 4 \\
\hline & $\begin{array}{l}\text { 'UX’ AND } \\
\text { ‘model’ AND } \\
\text { ‘online system’ }\end{array}$ & 3 & 0 & 0 \\
\hline \multirow{2}{*}{$\begin{array}{l}\text { Elsevier } \\
\text { Science } \\
\text { Direct }\end{array}$} & $\begin{array}{l}\text { 'user experience' } \\
\text { AND 'model' } \\
\text { AND 'online } \\
\text { system' }\end{array}$ & 337 & 192 & 2 \\
\hline & $\begin{array}{l}\text { 'UX' AND } \\
\text { 'model' AND } \\
\text { 'online system' }\end{array}$ & 60 & 11 & 0 \\
\hline \multicolumn{2}{|l|}{ Total } & 503 & 227 & 6 \\
\hline
\end{tabular}

After conducting a final review of relevant publications related to online systems, the authors analysed the papers in terms of domain of UX Model, instrument used, number of participants, and dimensional measurement, which are based on System and software Quality Requirements and Evaluation (SQuaRE) such as Measurement of quality in use (ISO 25022:2016) and Measurement of system and software product quality (ISO 25023:2016). These two ISOs were used as a guidance to determine the dimensions that have similar descriptions in the various existing UX evaluation models, and to ensure consistency of the terms used in the identification of common dimensions in this domain. ISO standards are widely used in the field of Human-Computer Interaction (HCI) [28]. The current study has reviewed six papers that were shortlisted in order to identify the gaps in the existing UX evaluation models and to answer research question 1 (RQ 1). Meanwhile, the components of a conceptual UX evaluation model for 
online systems have been developed based on the gaps identified and included the important dimensions from the literature in order to answer the RQ 2. Therefore, the study answered the RQ by conducting the paper review, identified the gaps, and then developed a new conceptual UX evaluation model.

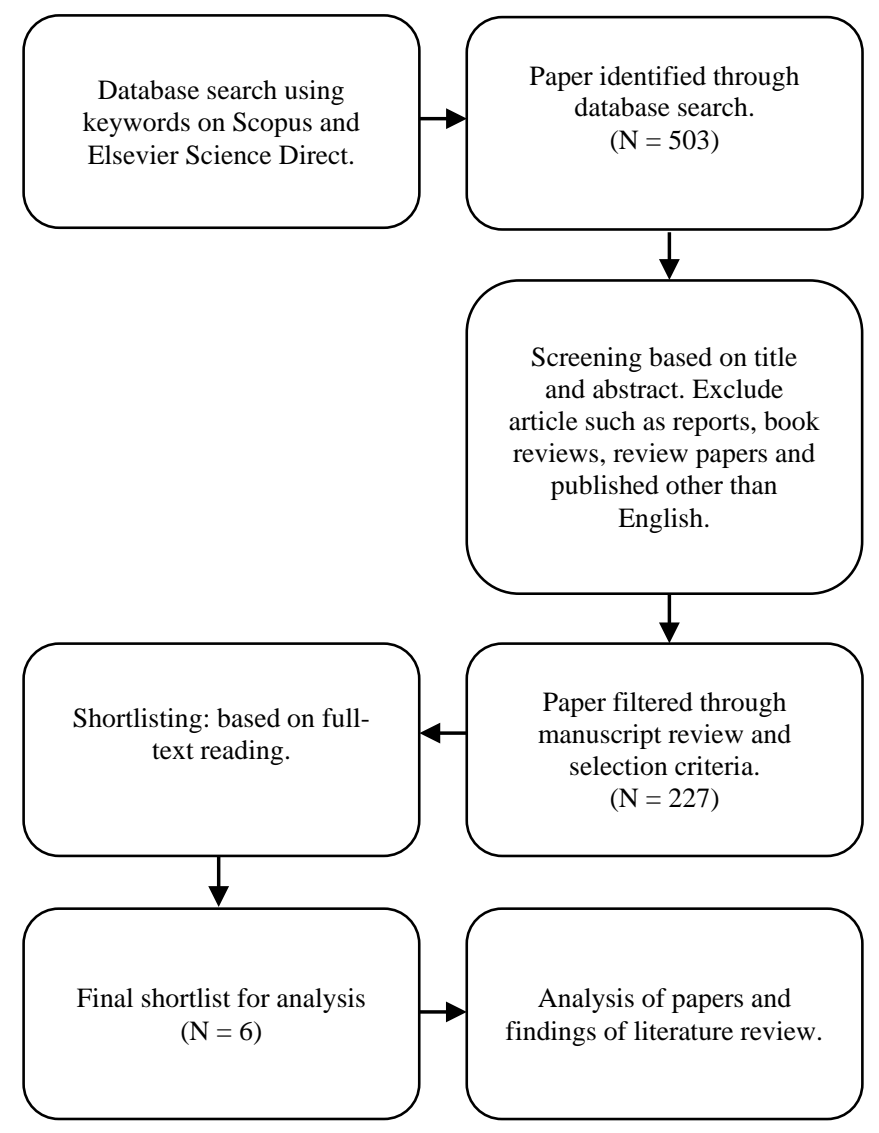

Fig. 1. Flow of Literature Review Methodology.

\section{RESUlt AND DISCUSSION}

There are various UX evaluation models or frameworks in the literature that have been introduced. However, these models are inadequate for online system measurement because these models are lacking in terms of important dimensions, criteria, and metrics. This study used ISO 25022:2016 and ISO 25023:2016 as guidance by referring to their description and categorisation of the dimensions in the UX evaluation model since there are various dimensional measurements in the literature. This section discusses existing UX evaluation models in the literature that have been identified in Section 3, and a summary of these models is presented in Table I by extracting important aspects such as domain of UX Model, instrument used, number of participants, dimensional measurement, other dimensions used (Based on ISO 25022:2016 and ISO 25023:2016), and the identified remarks or gaps.

\section{A. E-commerce's UX Evaluation Model}

In the work by [18], it is mentioned that improved user experience can attract new users, increase visitor numbers, and transaction volume of the system. The model was developed to evaluate e-commerce websites. The study's strength is that it employs the Fuzzy Comprehensive Evaluation Method, which improves the model by implementing specific steps to enable systematic evaluation, including the use of triangular fuzzy number theory, methods of psychological stratification, and weighting factors. Six experts in the field of e-commerce evaluated the model. The model developed by [18] consists of three dimensions: Visceral, behavioural, and reflective, and has verification. Based on ISO 25022:2016 and ISO 25023:2016, this model has emotional and functionality dimensions. However, this model does not provide dimension with criteria, and no metric is provided for online system measurement. Besides that, among the weaknesses of the model is that information can be lost by criteria's aggregation as it is based on probability and possibility measurement [through Analytic Hierarchy Process (AHP)] [29], [30]. Therefore, there is a need to provide dimensions, criteria, and metrics of the proposed model for online systems because these three components will provide clear measurement for evaluation. Fig. 2 shows the model developed.

\section{B. Testing of UX Model with News Sites}

The study by [15] has established a model that constitutes a fundamental theory for evaluating news websites, and is theoretically applicable to all UX studies. The model is expanded to estimate how satisfied users are with news websites. Instrumental qualities, non-instrumental qualities, and emotional responses are among the UX components that exist in this model. The strength of the model is determined by the measurement of instrumental qualities and noninstrumental qualities using AttrakDiff2 [31]. Meanwhile, emotional responses are measured through the Positive and Negative Affect Schedule (PANAS) elements [32]. Based on the ISO standard, this model consists of usefulness, emotional (ISO 25022:2016), and trust dimensions (ISO 25023:2016). However, the weaknesses of this model are broad measurements. For instance, pragmatic and hedonic qualities do not have criteria and metrics that are specifically for evaluation measurement. The model is also only for testing news sites and online news. Therefore, there is a need to provide dimensions, criteria, and metrics of the proposed model for online systems. Fig. 3 shows the developed model for testing news sites.

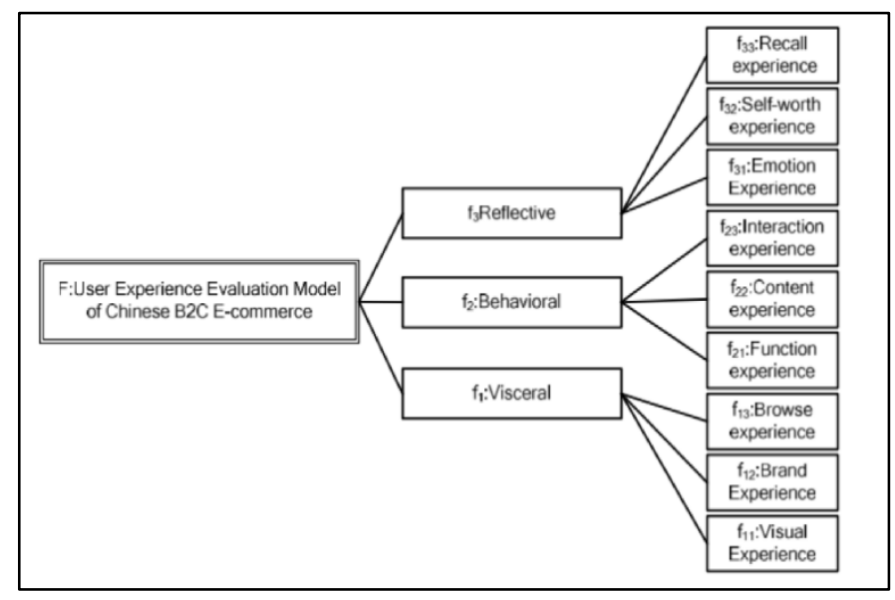

Fig. 2. Improved Hierarchical Model of p E-commerce's [18]. 


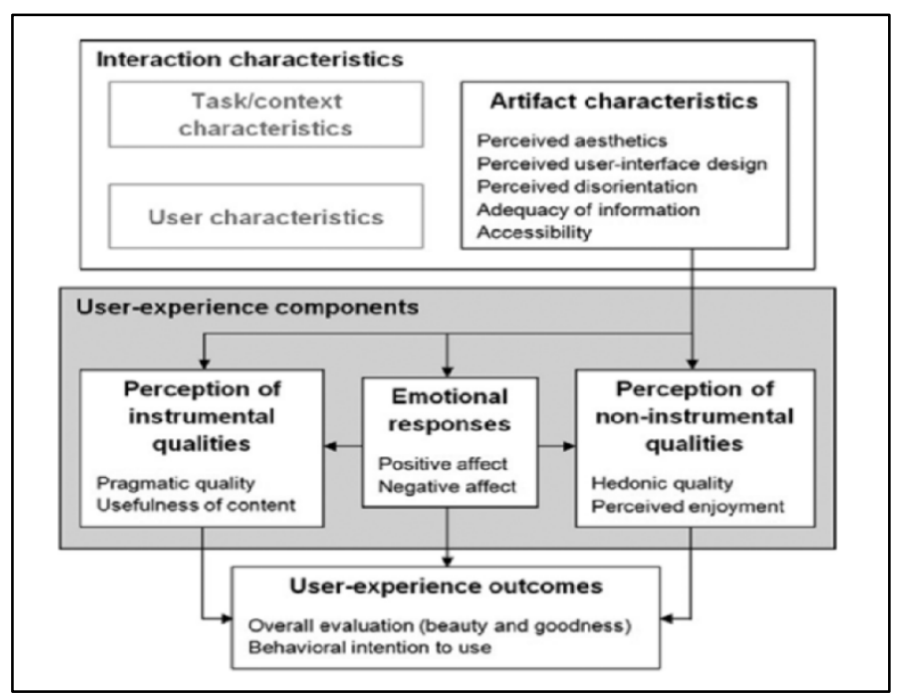

Fig. 3. High-Level Representation of the Model of UX with News Sites [15].

\section{Security and Usability Evaluation Model for e-Banking}

The work by [19] investigated frameworks or models, including approaches for evaluating e-banking security and usability. Their study combines a collection of frameworks that were related to security and usability properties such as the following: (1) interface; (2) navigation; (3) content; (4) offered services; (5) registration and transaction procedure; and (6) multi-factor authentication methods. This combination is called the hybrid security and usability evaluation model. Based on the ISO 25023:2016 standard, this model consists of usability and security dimensions. The strength of this model is it is able to evaluate e-bank assets that are accessible to the public, and it covers 13 different security and usability categories with more than 160 metrics. Finally, this model comprises the security evaluation part of the framework with 72 metrics, and usability evaluation part with 97 metrics. However, the weakness of this model is the unclear presentation of dimensions in the model with criteria and metrics. Moreover, security and usability evaluations are required to be considered in the quality improvement process; thus, these dimensions need to be designed and tested as part of the quality improvement process in order to ensure their coherence with other parts of the process [19]. Therefore, it can be concluded that the presentation of this model can be improved for evaluation and online system measurement. Fig. 4 shows the proposed security and usability evaluation model.

\section{Evaluation of the Modified Immersive Virtual Environment (UXIVE) Model}

The UXIVE model has been introduced by [24], in which the constructed model components are derived from existing models. The method used was quantitative (questionnaire), and the findings were analysed for model validation using Structural Equation Modelling (SEM). The sample size is large (152 respondents); thus, SEM has been employed for statistical analysis. The strength of this model is validated, which comprises ten new UX dimensions, namely presence, immersion, engagement, skill, emotion, flow, usability, technology adoption, judgement, and experience consequence for the edutainment field. Moreover, the model can be used in a variety of disciplines, including industrial and collaborative settings. Based on the ISO standard, this model consists of emotional (ISO 25022:2016) and usability dimensions (ISO 25023:2016). However, the weaknesses of this model are this model is general due to the lack of criteria and metrics that link to the dimensions. The measurement for the online system should be clear in order to get better results for evaluation. Therefore, the dimensions, criteria, and metrics of the proposed model for online systems are required. The UXIVE model is depicted in Fig. 5.

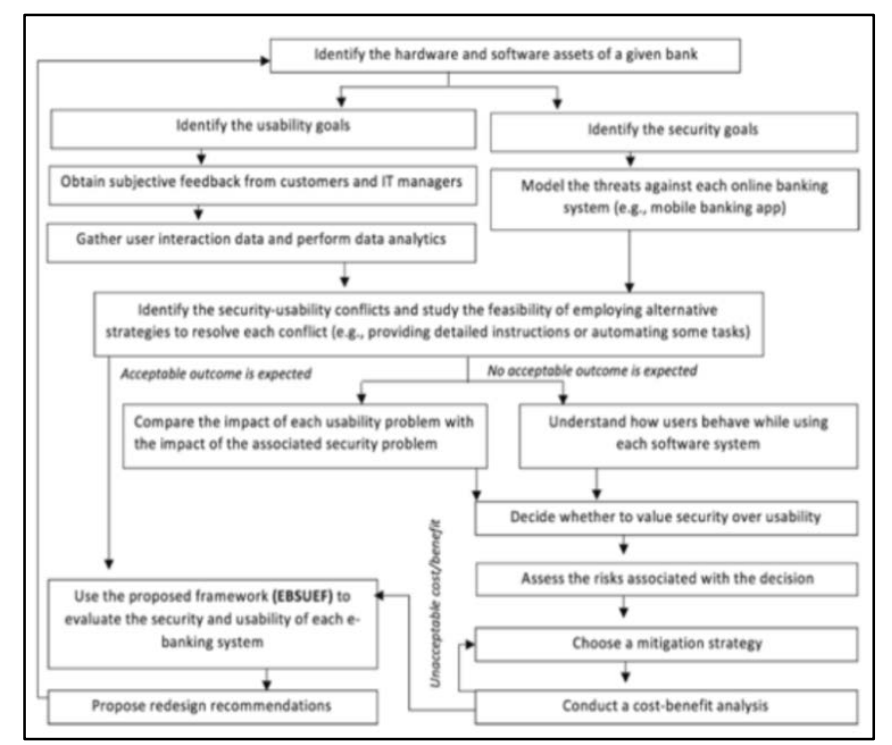

Fig. 4. The Proposed Security and usability Evaluation Model [19].

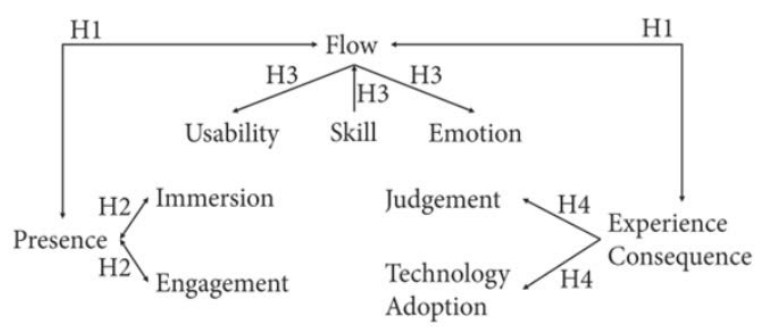

$\stackrel{\mathrm{Hn}}{\longrightarrow}$ Influence of a component over another one (hypothesis $\mathrm{n}$ )

Fig. 5. The Hypothesised UXIVE Model [24].

\section{E. UX Evaluation Model on Mobile Terminal Products}

The Content Interaction Vision Model (CIV Model) was developed by [20]. Content, interaction, and vision are the three UX dimensions of the CIV model. Their study examines the important dimensions by using the Heuristic evaluation approach and Nielsen's ten (10) usability principles. The strength of the model is that the results of the dimensions are displayed in the form of a radar chart, which uses a set of questionnaires from the System Usability Scale (SUS) for the evaluation. Based on ISO 25023:2016), this model consists of functionality and usability dimensions. In the same vein, the 
study by [33] also used SUS and proposed the UX Maturity Model for e-commerce websites, which focused on the three cores of user experience, namely user research, visual design, and user testing. This shows that the UX evaluation conducted with other instruments could strengthen the findings of the study. However, Huang et al.'s [20] model evaluation focused more on the usability principle in order to construct the CIV evaluation method and it has a subjective metric. Moreover, this model has no verification for the feasibility of the evaluation model. Therefore, it is necessary to identify the appropriate dimension, criteria, and metrics for online systems to get clear measurement of evaluation regarding user experience (UX). Fig. 6 shows the CIV Evaluation Model of User Experience.

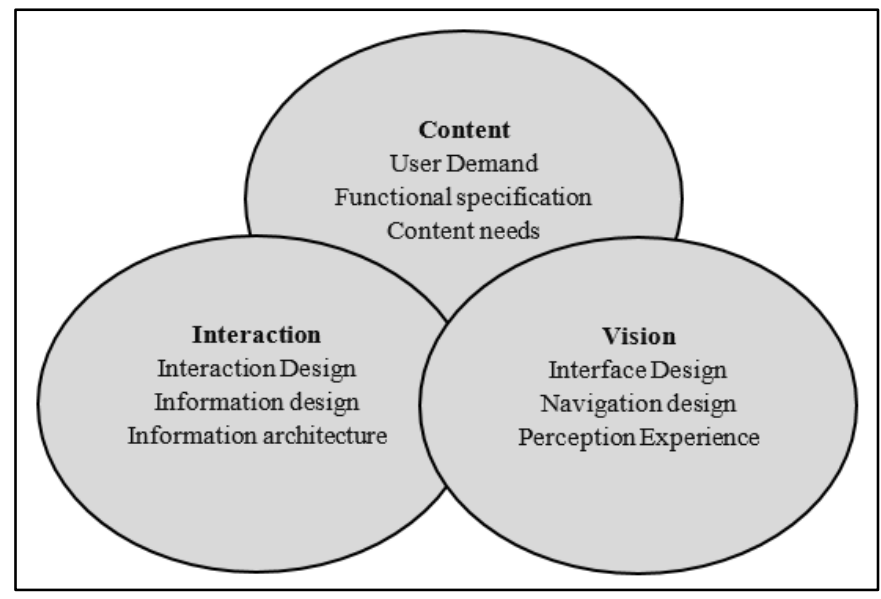

Fig. 6. CIV Evaluation Model of user Experience [20].

\section{F. Loyalty Model for E-commerce Recommender Systems}

The study by [34] about the use of an e-commerce recommender agent explores the major determinants in the establishment of female online shopper loyalty. Then, a new model is introduced, developed, and analysed in order to improve e-commerce consumer loyalty via the recommender systems. The strength of the model is the use of SEM to analyse the relationships between independent and dependent variables for quantitative research. Their study used the SEM tool because it combines factor analysis, path analysis, and multiple regression analysis to evaluate construct relationships [34]. Moreover, based on ISO 25023:2016, the dimensions in this model that were measured are usability, transparency, satisfaction, and trust. However, this model did not provide clear criteria and metrics for evaluation, which consists of dimensions and relationships for each construct. Their research also has some limitations in terms of data dissemination and collection because the evaluation only involved one ecommerce platform, whereby it could not be generalised to the population studied. In addition, the proposed model requires two items: Experience and search-characteristic products for future research [34]. Therefore, there is a need for dimensions with criteria, and metrics of the model as well as a need to consider the experience element of the model in future research. Fig. 7 shows the Loyalty Model for E-commerce Recommender Systems. Meanwhile, Table II shows the summary comparison of existing UX evaluation models or frameworks identified.

Based on the model analysis in Table II above, the models were purposely developed for e-commerce [18], testing a news site [15], e-banking system [19], edutainment [24], mobile terminal products [20], and an e-commerce recommender system [34]. Thus, there is no generic online system measurement that can be used as each one is tailored to a specific system. This means that existing UX models are more focused on systems such as e-commerce, e-news, e-banking, and mobile product but there is no guided measurement for online system as overall such as for online reservation, online booking including e-government, e-procurement.

The model by [15] has provided subjective metrics, but it is for news websites. Meanwhile, Huang et al. [20] did not present how they performed verification for the feasibility of the evaluation model. In addition, the [34] model does not have criteria for the measurement. Moreover, the model by Liu et al. [18], Alarifi et al. [19], and Tcha-Tokey et al. [24] also did not provide metrics for UX evaluation. The dimensions with criteria and metrics in the existing model are lacking in order to give clear description to the users about the measurement and conducting evaluation. Thus, these studies show that there is a lack in terms of dimensions with criteria and metrics in the existing models that are specifically for online system measurement. Hence, this current study motivates the researchers to develop a new conceptual UX evaluation model for online systems by identifying the important dimensions for better measurement.

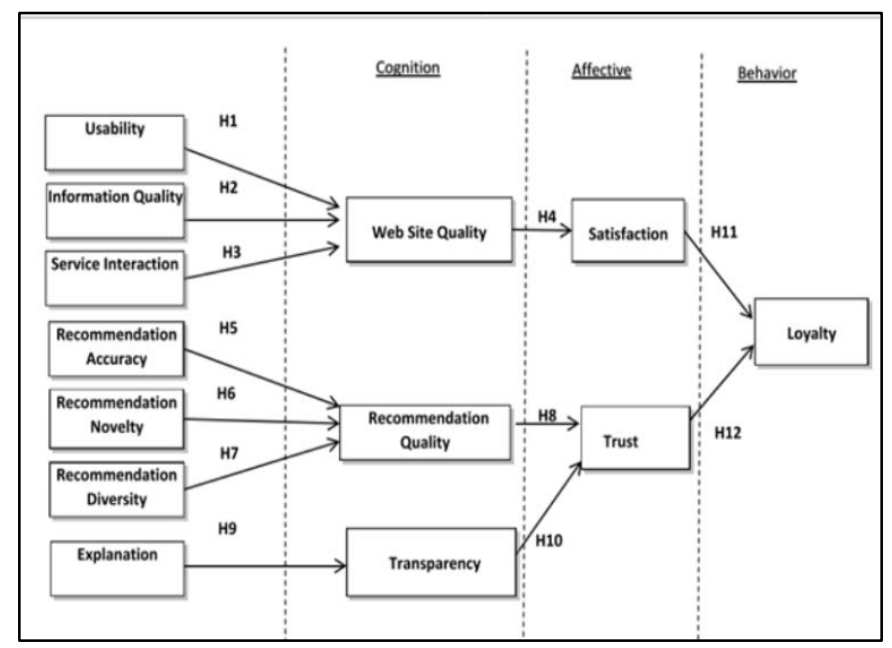

Fig. 7. Loyalty Model for E-commerce Recommender Systems [34]. 
TABLE II. THE SUMMARY COMPARISON OF EXISTING UX EVALUATION MODELS OR FRAMEWORKS

\begin{tabular}{|c|c|c|c|c|}
\hline Authors & $\begin{array}{l}\text { Instrument and } \\
\text { Number of Participants }\end{array}$ & Dimensions that measured & $\begin{array}{l}\text { Other Dimensions (Based on ISO } \\
\text { 25022: } 2016 \text { and ISO 25023: 2016) }\end{array}$ & Remarks/ Gaps \\
\hline $\begin{array}{l}\text { Liu et al. } \\
{[18]}\end{array}$ & $\begin{array}{l}\text { Questionnaire } \\
\text { (6 experts) }\end{array}$ & $\begin{array}{l}\text { Visceral, Behavioural, } \\
\text { Reflective. }\end{array}$ & $\begin{array}{l}\text { Functionality, } \\
\text { Emotional. }\end{array}$ & $\begin{array}{l}\text { No UX metric provided } \\
\text { in the model. } \\
\text { Model for e-commerce site. }\end{array}$ \\
\hline $\begin{array}{l}\text { Aranyi and } \\
\text { van Schaik } \\
{[15]}\end{array}$ & $\begin{array}{l}\text { Questionnaire } \\
\text { AttrakDiff2, } \\
\text { PANAS } \\
\text { (85) }\end{array}$ & $\begin{array}{l}\text { Ease of use, Perceived } \\
\text { Enjoyment, Beauty and } \\
\text { Goodness, Behavioural } \\
\text { intention. }\end{array}$ & $\begin{array}{l}\text { Usefulness, Trust, } \\
\text { Emotional, } \\
\text { Satisfaction. }\end{array}$ & $\begin{array}{l}\text { Has subjective metrics but it is for } \\
\text { news websites. } \\
\text { Model for } \\
\text { designer (online news or interactive } \\
\text { product) }\end{array}$ \\
\hline $\begin{array}{l}\text { Alarifi et al. } \\
\text { [19] }\end{array}$ & $\begin{array}{l}\text { Users using web portals } \\
\text { from the five banks }\end{array}$ & - & $\begin{array}{l}\text { Usability, } \\
\text { Security }\end{array}$ & $\begin{array}{l}\text { Do not provide criteria and metrics of } \\
\text { model. } \\
\text { Does not provide any prioritisation of } \\
\text { metrics. } \\
\text { Model for e-banking systems. }\end{array}$ \\
\hline $\begin{array}{l}\text { Tcha-Tokey } \\
\text { et al. } \\
\text { [24] }\end{array}$ & $\begin{array}{l}\text { Questionnaire } \\
(152)\end{array}$ & $\begin{array}{l}\text { Presence, engagement, } \\
\text { immersion, flow, skill, } \\
\text { experience consequence, } \\
\text { judgement, and technology } \\
\text { adoption. }\end{array}$ & Usability, Emotional & $\begin{array}{l}\text { Only have UX dimensions. } \\
\text { No metrics provided in the model. } \\
\text { Model for edutainment field. }\end{array}$ \\
\hline $\begin{array}{l}\text { Huang et al. } \\
\text { [20] }\end{array}$ & $\begin{array}{l}\text { Experiment } \\
\text { (10) }\end{array}$ & $\begin{array}{l}\text { Content } \\
\text { Interaction } \\
\text { Vision }\end{array}$ & $\begin{array}{l}\text { Functionality, } \\
\text { Usability }\end{array}$ & $\begin{array}{l}\text { No verification for the feasibility of the } \\
\text { evaluation model. } \\
\text { For mobile and design of online } \\
\text { product only }\end{array}$ \\
\hline $\begin{array}{l}\text { Ali et al. } \\
\text { [34] }\end{array}$ & $\begin{array}{l}\text { Survey questionnaire } \\
(300)\end{array}$ & $\begin{array}{l}\text { Web Site Quality, } \\
\text { Recommendation Quality, } \\
\text { Loyalty }\end{array}$ & $\begin{array}{l}\text { Usability, } \\
\text { Transparency, } \\
\text { Satisfaction, } \\
\text { Trust }\end{array}$ & $\begin{array}{l}\text { Has dimensions whereby it is a } \\
\text { construct, but do not have criteria. } \\
\text { Model for e-Commerce Recommender } \\
\text { Systems. }\end{array}$ \\
\hline
\end{tabular}

Moreover, it also shows that there are various dimensions measured by the existing models, and the researcher used the ISO standard such as System and Software Quality Requirements and Evaluation (SQuaRE) which Measurement of quality in use (ISO 25022:2016) and Measurement of system and software product quality (ISO 25023:2016) as a guidance in order to identify and categorise appropriate UX dimensions that are similar to each model. Thus, the models by Alarifi et al. [19], Tcha-Tokey et al. [24], Huang et al. [20], and Ali et al. [34] have similar descriptions of dimensions, for example, usability. Meanwhile, the model by Liu et al. [18] and Huang et al. [20] have the functionality dimension. Besides that, the emotional dimension has been measured by the model by Liu et al. [18], Aranyi and van Schaik [15], and Tcha-Tokey et al. [24]. Furthermore, the model by Aranyi and van Schaik [15] and Ali et al. [34] have the trust and satisfaction dimension in their measurement. Therefore, this argument shows that the common UX dimensions for evaluation for online system measurement are usability, functionality, emotional, trust, and satisfaction. These dimensions can be considered in measurement for online systems.

On the other hand, based on ISO 25022:2016, the usability characteristic comprises efficiency, effectiveness, and satisfaction, whereby these dimensions can be considered in the model for online system measurement. However, from the analysis that has been done, the measurement of these dimensions requires UX components, so that the evaluation of users can be conducted more accurately and correctly, for example, considering the pragmatic and hedonic qualities with UX metrics. Based on Fig. 8 below, it shows the gaps flow from existing UX evaluation models that were derived from Table II. The purpose of this figure is to provide an overview of the models that have been identified from the literature, including the gaps and the requirements of the developed conceptual UX evaluation model. As mentioned earlier, this study identified six existing evaluation models related to user experience and online systems. The flow in Fig. 8 shows that the UX evaluation model requires UX dimensions, criteria, and metrics for the model of online systems in order to get a clear measurement illustration.

Besides that, the findings also revealed that any development of the UX evaluation model for online systems should consider prioritisation for the metrics because it will determine which dimensions need to be prioritised for the evaluation measurement [19]. Furthermore, there is a need for the verification for the feasibility of the model to be concerned in any UX evaluation model development. The existing UX model is also still not focus on measuring emotions. Therefore, it can be concluded that there is a need for dimensions with criteria and metrics for online system measurement. Among the dimensions that can be considered in the measurement are efficiency, effectiveness, satisfaction, functionality, emotional, and trust. Thus, these findings addressed important components with justification for an online system measurement. 


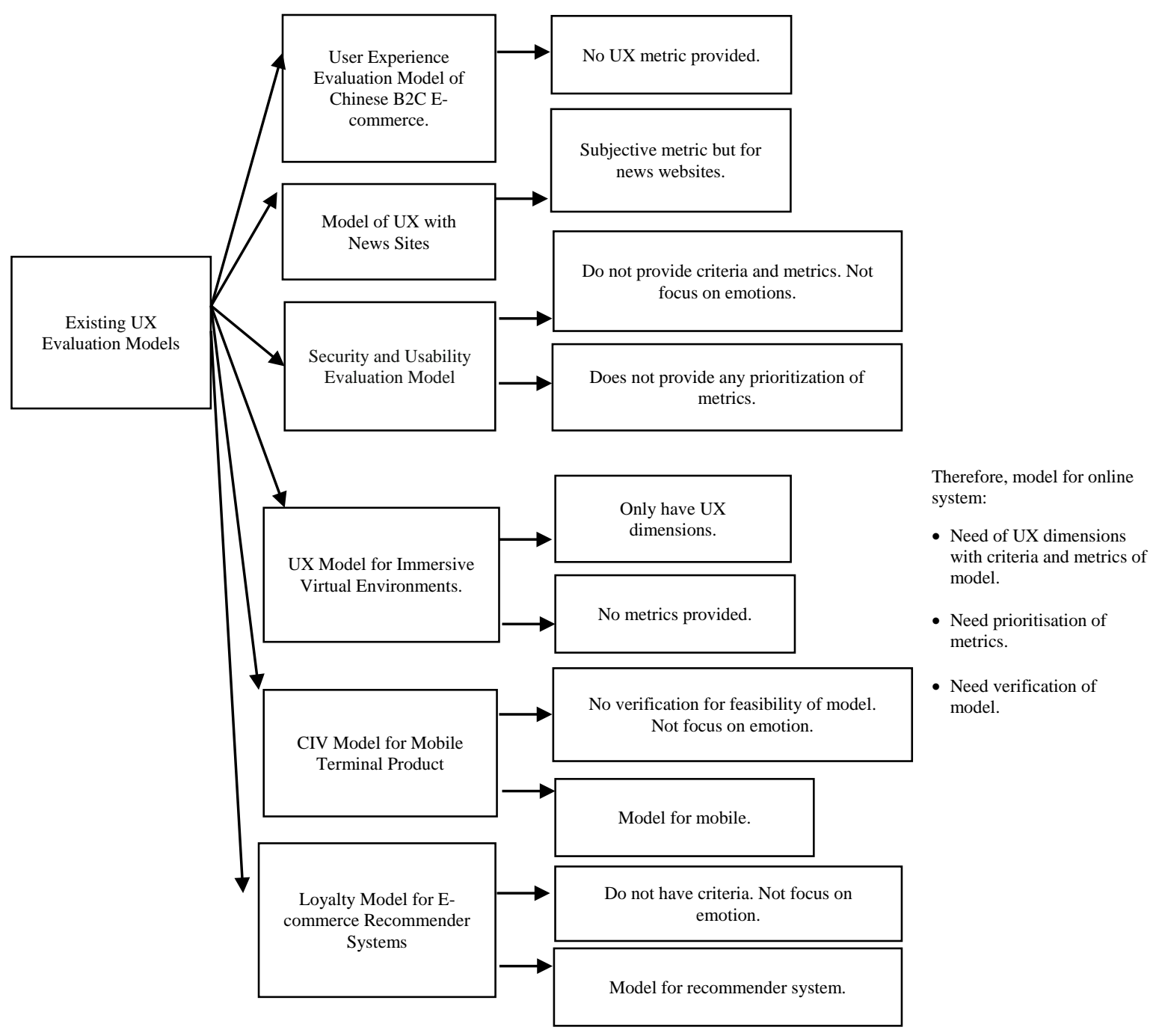

Fig. 8. Gaps of Existing UX Evaluation Models.

\section{G. Development of Conceptual UX Evaluation Model for Online Systems}

Fig. 9 shows the conceptual UX evaluation model for online systems. This conceptual model was proposed to fill the gaps in the literature that has been identified and discussed in Section 4. The conceptual model in this study is adapted from the Aranyi and van Schaik model [15] because this model consists of interaction characteristics such as user characteristic, task characteristic, and artifact characteristic; and user experience components such as perception of instrumental qualities, perception of non-instrumental qualities, and emotional responses. As mentioned earlier, all these components are important and needed because they are core components of experience whereby users' perception, including emotions, are evaluated during the interaction with the system [16]. User characteristic refers to user knowledge or skill such as education, system experience, personality or role, and language proficiency [35]. While task characteristic refers to business workflow in the study by Seffah et al. [36], another study refers to complexity and involvement in primary tasks [35]. Besides that, artifact characteristic refers to the online system used by the user.
There are many examples of online systems such as online ticketing systems, online management systems, online billing systems and so on. Online systems are also implemented by the e-government, e-procurement systems, and others. Thus, the findings are significant for these type of online systems to be considered because they can refer to this conceptual UX evaluation model that will be developed for system measurement and enhance their positive user experiences. Meanwhile, instrumental qualities can be related to technical features, for example, task suitability, self-descriptiveness, and controllability [16]. Non-instrumental qualities can be related to design features, for example, material, form, and combinations of colour [16]. The perception of noninstrumental qualities, emotions, and the perception of instrumental qualities are influenced by interaction characteristics, which consist of system function, user, and context, whereby it has experiential consequences such as overall experience, acceptance, intention to use, and alternative choice [37]. Thus, these core UX components of experience are important for measurement by the organisation, especially those that use online systems. 
Based on the findings in Table II which have been discussed, a conceptual model needs to have dimensions with criteria and metrics of model, prioritization of metrics, and model verification. Moreover, based on the discussion earlier (Table II), the dimensions that can be considered in the measurement are efficiency, effectiveness, satisfaction, functionality, emotional, and trust. However, the conceptual model development is designed by including appropriate dimensions and linking with criteria and metrics in order to provide clear measurement for online systems. Another study has provided UX dimensions with metrics, but it is for mobile learning [38].

According to [39], instrumental qualities are related to efficiency, effectiveness, navigation, system visibility, and others. Meanwhile, [40] discussed that non-instrumental qualities are related to aesthetics, innovativeness, and originality. There has been research that places satisfaction under the category of instrumental qualities [39]. However, attractiveness and satisfaction could be placed under noninstrumental qualities or hedonic qualities based on literature support and data from systematic literature review (SLR) as conducted by [41] study. Based on this argument, satisfaction can be measured as a hedonic quality, whereby it considers the overall experiences of the system by the users [39]. Therefore, based on these arguments, efficiency and effectiveness can be placed in the instrumental qualities, while attractiveness and satisfaction can be placed in the non-instrumental qualities as shown in Fig. 9. These dimensions also show that the proposed conceptual UX evaluation model for online system has been extended from [15] terms of dimensions as shown in Fig. 9.

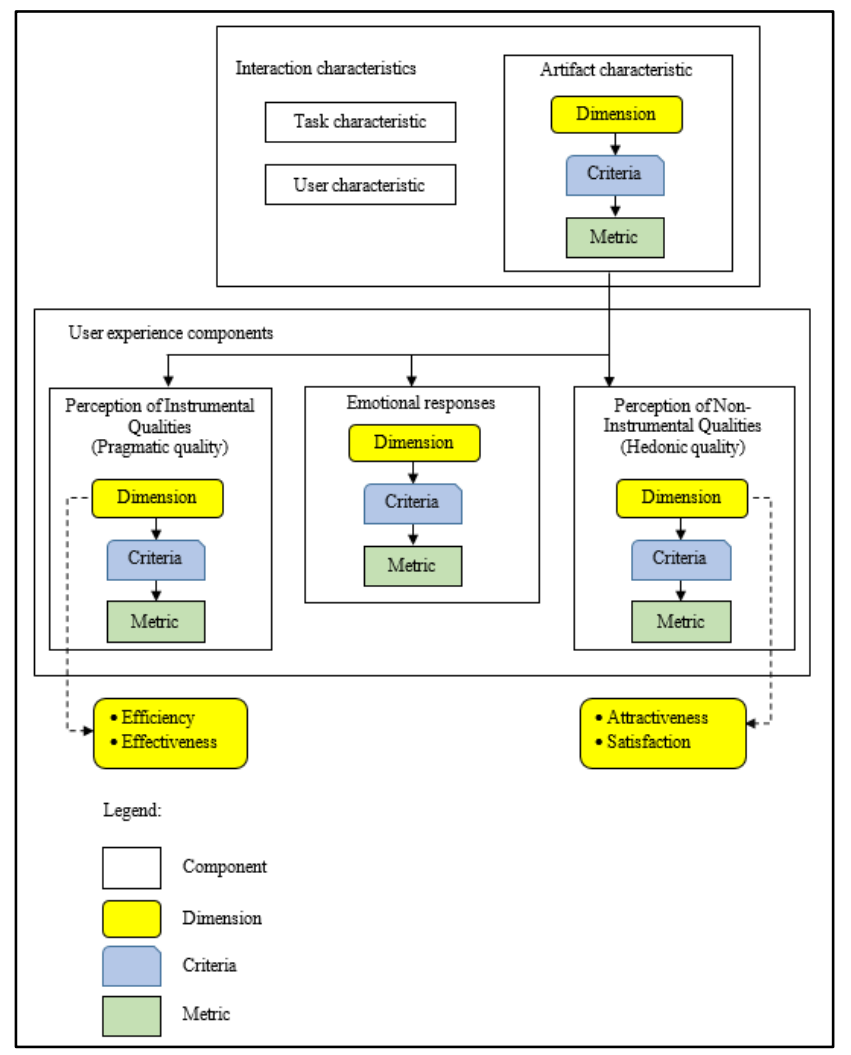

Fig. 9. A Conceptual UX Evaluation Model for Online Systems.
Based on Fig. 9, a conceptual UX evaluation model for online systems has two parts, which are interaction characteristic and user experience components. Interaction characteristics consist of components such as task characteristic, user characteristic, and artifact characteristic. The conceptual model that has artifact characteristic links to user experience components, which has perception of instrumental qualities (pragmatic quality), emotional responses, and perception of non-Instrumental qualities (hedonic quality) whereby it is adapted from Aranyi and van Schaik's model [15]. The new conceptual UX evaluation model is extended by including the dimensions, criteria, and metrics in the user experience components. This conceptual model also revealed the important dimension for online systems, namely efficiency and effectiveness for pragmatic quality; and attractiveness and satisfaction for hedonic quality. On the contrary, the study by [7] stated that the sub-category of emotion relates to attractiveness, enjoyment, and fulfilment. However, this study placed attractiveness under hedonic as investigated by [41] study. Besides, instrumental and non-instrumental qualities could influence the reactions of users emotionally in the use of the system [42].

By applying this conceptual UX evaluation model for online system measurement, the organisation can provide a positive experience for their users with the system. Therefore, this conceptual UX evaluation model for online systems can contribute to system developers and designers as a guidance in order to measure users' experiences because the model representation is flexible, simple, and easy to understand. In addition, the novelty of this model development consists of the UX dimensions, criteria, and metrics whereby it will give a clearer structure of the model for evaluation measurement not only to the system developer and designers, but also benefits researchers for future studies.

\section{CONCLUSION AND FUtURE WORK}

Online systems are becoming more important sources of services for many people; research on the model of online systems is a necessity because it is important for any quality improvement process. This paper conducted a literature review from online databases such as Scopus and Elsevier Science Direct about the current state of UX evaluation for online systems, and the researchers have identified relevant papers that were finally selected for full review and critically analysed. It seems that the existing UX evaluation models do provide dimensions, however, they do not have criteria and metrics in supporting for more detailed and guided the measurement. It is found that many of the developed UX evaluation models have weak links between dimensions, criteria, and metrics in the evaluation measurement. The analysis of papers was based on System and Software Quality Requirements and Evaluation (SQuaRE) such as Measurement of quality in use (ISO 25022:2016) and Measurement of system and software product quality (ISO 25023:2016). After identifying gaps in the previous literature on existing UX evaluation models, then this study proposed a new conceptual UX evaluation model for online systems and extended the model by adding important dimensions needed for measurement such as efficiency, effectiveness, attractiveness and satisfaction. Moreover, the user experience component 
such as pragmatic quality, emotional responses and hedonic quality also are needed for measurement. The newly developed conceptual UX evaluation model is expected to aid decision makers in resolving any evaluation issues, for instance, the early stages in the development process of the model for online systems. Thus, the goal of this study has been achieved by analysed the UX evaluation models and proposed a conceptual UX evaluation model for online systems that can benefit system developers, designers, and also researchers. It believes that a developed model consisting of dimensions, criteria, and metrics is necessary to ensure the comprehensiveness of the online system measurement in the future.

Future research can be conducted to explore more UX dimensions for online systems in order to get more understanding for evaluation. For future studies, further identification of general criteria and metrics for online systems will be conducted. Therefore, this paper provides a new conceptual UX evaluation model for online systems whereby it is significant to the system developers and designers because they can use the findings of this study in the system development phase and researchers can use it as a guide for future studies. Findings from this paper are also important for system developers and designers to gain an in-depth understanding of the important dimensions of online system measurement such as for e-commerce and it can be used as a basis or guide to redesign existing systems to enhance positive user experience.

\section{ACKNOWLEDGMENT}

This research was supported by Ministry of Higher Education (MoHE) of Malaysia through Fundamental Research Grant Scheme (FRGS/1/2019/ICT01/UUM/02/4). The authors also want to thank Department of Polytechnic and Community Colleges Education (Hadiah Latihan Persekutuan) for their support.

\section{REFERENCES}

[1] J. Sriarunrasmee and C. Anutariya, "The Development of One Stop Service Online System based on User Experience Design and AGILE Method," in ACM International Conference Proceeding Series, 2020, no. January, pp. 64-69.

[2] P. Sukmasetya, H. B. Santoso, and D. I. Sensuse, "Current EGovernment Public Service on User Experience Perspective in Indonesia," in International Conference on Information Technology Systems and Innovation (ICITSI), 2019, pp. 159-164.

[3] M. Luca, "Designing online marketplaces: Trust and reputation mechanisms," Innov. Policy Econ., vol. 17, no. 1, pp. 77-93, 2017.

[4] A. Rangaswamy, N. Moch, C. Felten, G. van Bruggen, J. E. Wieringa, and J. Wirtz, "The Role of Marketing in Digital Business Platforms," J. Interact. Mark., vol. 51, pp. 72-90, 2020.

[5] M. R. Razlini, "Challenges and issues in Malaysian e-government," Electron. Gov., vol. 13, no. 3, pp. 242-273, 2017.

[6] K. K. Soong, E. M. Ahmed, and K. S. Tan, "Factors Affecting Malaysia's SMEs in Using Public Electronic Procurement," J. Inf. Knowl. Manag., vol. 19, no. 2, pp. 1-22, 2020.

[7] L. Hasan, "Examining User Experience of Moodle e-Learning System," Int. J. Adv. Comput. Sci. Appl., vol. 12, no. 11, pp. 358-366, 2021.

[8] D.-O. Ignacio, L. Gustavo, L. Quesada, and L. A. Guerrero, "UX Evaluation with Standardized Questionnaires in Ubiquitous Computing and Ambient Intelligence: A Systematic," Adv. Human-Computer Interact., pp. 1-22, 2021.

[9] L. Luther, V. Tiberius, and A. Brem, "User experience (UX) in business, management, and psychology: A bibliometric mapping of the current state of research,” Multimodal Technol. Interact., vol. 4, no. 18, pp. 119, 2020.

[10] V. Klisman et al., "LogMe: An Application for Generating Logs in Immersive Interactions for UX Evaluation,” in Proceedings ofthe 23rd International Conference on Enterprise Information Systems (ICEIS 2021), 2021, vol. 2, pp. 549-556.

[11] I. Pettersson, F. Lachner, A. K. Frison, A. Riener, and A. Butz, “A bermuda triangle? - A review of method application and triangulation in user experience evaluation," in Conference on Human Factors in Computing Systems - Proceedings, 2018, pp. 1-16.

[12] Y. Qu and I. H. Chen, "Are emotions important for college teachers' intentions to use the online learning system? An integrated model of TAM and PAD,” Int. J. Inf. Educ. Technol., vol. 11, no. 2, pp. 73-83, 2021.

[13] B. Yang, Y. Liu, Y. Liang, and M. Tang, "Exploiting user experience from online customer reviews for product design,” Int. J. Inf. Manage., vol. 46, no. October 2018, pp. 173-186, 2019.

[14] C. M. MacDonald, "User Experience (UX) Capacity-Building: A Conceptual Model and Research Agenda," in Proceedings of the 2019 on Designing Interactive Systems Conference, 2019, pp. 187-200.

[15] G. Aranyi and P. van Schaik, "Testing a model of user-experience with news websites,” J. Assoc. Inf. Sci. Technol., vol. 67, no. 7, pp. 15551575, 2016.

[16] M. Minge and M. Thüring, "Hedonic and pragmatic halo effects at early stages of User Experience,” Int. J. Hum. Comput. Stud., vol. 109, no. January 2018, pp. 13-25, 2017.

[17] M. Mazmela, G. Lasa, E. Aranburu, I. Gonzalez, and D. Reguera, "TAMUX model for industrial HMI evaluation from UX and task performance perspective,” ACM Int. Conf. Proceeding Ser., vol. 19, pp. 1-2, 2018.

[18] X. X. Liu, Q. Y. Liu, W. Wang, C. M. Huang, and W. S. Li, "Research on the E-commerce's user experience evaluation model," Appl. Mech. Mater., vol. 427-429, pp. 2859-2863, 2013.

[19] A. Alarifi, M. Alsaleh, and N. Alomar, "A model for evaluating the security and usability of e-banking platforms," Computing, vol. 99, no. 5, pp. 519-535, 2017.

[20] Z. Huang, Y. Hong, and X. Xu, "Design and research on evaluation model of user experience on mobile terminal products," in International Conference on Applied Human Factors and Ergonomics, 2020, pp. 198206.

[21] G. Pisoni, "Moodle vs Sakai: Evaluating user experience for online entrepreneurship education,” in ICETA 2019 - 17th IEEE International Conference on Emerging eLearning Technologies and Applications, Proceedings, 2019, pp. 836-840.

[22] K. E. S. Souza, M. C. R. Seruffo, H. D. De Mello, D. D. S. Souza, and M. M. B. R. Vellasco, "User Experience Evaluation Using Mouse Tracking and Artificial Intelligence,” IEEE Access, vol. 7, pp. 9650696515, 2019.

[23] I. Atoum, J. Almalki, S. M. Alshahrani, and W. Al Shehri, "Towards Measuring User Experience based on Software Requirements,” Int. J. Adv. Comput. Sci. Appl., vol. 12, no. 11, pp. 325-331, 2021.

[24] K. Tcha-Tokey, O. Christmann, E. Loup-Escande, G. Loup, and S. Richir, "Towards a model of user experience in immersive virtual environments," Adv. Human-Computer Interact., vol. 2018, pp. 1-10, 2018.

[25] L. Chow, "BINUS Online Learning Web User Experience Improvement,” Eng. Math. Comput. Sci. J., vol. 2, no. 1, pp. 5-13, 2020.

[26] I. Kangas, M. Schwoerer, and L. J. Bernardi, "Recommender systems for personalized user experience: Lessons learned at Booking.com," in 15th ACM Conference on Recommender Systems, RecSys 2021, 2021, pp. 583-586.

[27] S. Nandankar and A. Sachan, "Electronic procurement adoption, usage and performance: A literature review,” J. Sci. Technol. Policy Manag., vol. 11, no. 4, pp. 515-535, 2020.

[28] S. Ashok et al., "Measuring Public Value UX based on ISO / IEC 25010 Quality Attributes,” 3rd Int. Conf. User Sci. Eng., pp. 56-61, 2014. 
[29] R. D. F. S. M. Russo and R. Camanho, "Criteria in AHP: A systematic review of literature,” Procedia Comput. Sci., vol. 55, pp. 1123-1132, 2015.

[30] S. Oguztimur, "Why fuzzy analytic hierarchy process approach for transport,” Res. gate, no. September, pp. 1-19, 2015.

[31] M. Hassenzahl, S. Diefenbach, and A. Göritz, "Needs, affect, and interactive products - Facets of user experience,” Interact. Comput., vol. 22, no. 5, pp. 353-362, 2010.

[32] D. Watson, L. A. Clark, and A. Tellegen, "Development and Validation of Brief Measures of Positive and Negative Affect: The PANAS Scales,” J. Pers. Soc. Psychol., vol. 54, no. 6, pp. 1063-1070, 1988.

[33] M. C. Anchahua, L. V. Garnique, and J. A. Tarazona, "User Experience Maturity Model for Ecommerce Websites," in Congreso Internacional de Innovación y Tendencias en Ingeniería (CONIITI), 2018, pp. 1-6.

[34] R. Ali, O. Ibrahim, and M. Nilashi, "Loyalty of young female Arabic customers towards recommendation agents : A new model for B2C Ecommerce,” Technol. Soc., vol. 61, no. May, p. 101253, 2020.

[35] N. H. Chowdhury, M. T. P. Adam, and T. Teubner, "Time pressure in human cybersecurity behavior: Theoretical framework and countermeasures,” Comput. Secur., vol. 97, p. 101931, 2020.

[36] A. Seffah, M. Donyaee, R. B. Kline, and H. K. Padda, "Usability measurement and metrics: A consolidated model,” Softw. Qual J, vol. 14, no. 2, pp. 159-178, 2006.
[37] G. Gronier, "Measuring the first impression: testing the validity of the 5 second test,” J. Usability Stud., vol. 12, no. 1, pp. 8-25, 2016.

[38] N. Mohamad and N. L. Hashim, "UX Testing for Mobile Learning Applications of Deaf Children,” Int. J. Adv. Comput. Sci. Appl., vol. 12, no. 11, pp. 294-299, 2021.

[39] C. J. Van Staden, J. A. Van Biljon, and J. H. Kroeze, "Using a user experience evaluation framework for eModeration,” in 2017 Conference on Information Communication Technology and Society, ICTAS 2017 Proceedings, 2017, pp. 1-6.

[40] Z. Rasyida, M. C. Lam, A. B. Khairul Azmi, and I. Ahmad Khaldun, "User Experience Model for Remote Envenomation Consultation Mobile Application with Decision Support Ability,” Int. J. Adv. Sci. Eng. Inf. Technol., vol. 8, no. 4-2, pp. 1470-1479, 2018.

[41] M. S. A. B. A. Ghani and S. N. B. Wan Shamsuddin, "A Systematic Literature Review: User experience (UX) Elements in Digital Application for Virtual Museum,” Int. J. Adv. Trends Comput. Sci. Eng., vol. 9, no. 3, pp. 2801-2807, 2020.

[42] A. I. Nur, H. B. Santoso, and P. O. H. Putra, "The Method and Metric of User Experience Evaluation: A Systematic Literature Review," in International Conference on Software and Computer Applications, 2021, pp. 307-317. 